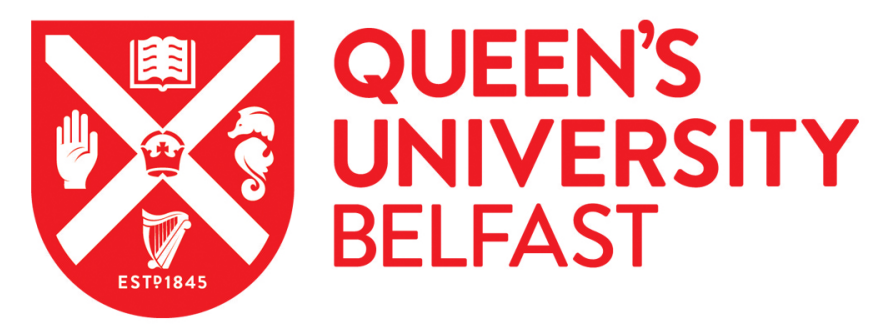

\title{
Initiating advance care planning on end-of-life issues in dementia: Ambiguity among UK and Dutch physicians
}

T. van der Steen, J., Galway, K., Carter, G., \& Brazil, K. (2016). Initiating advance care planning on end-of-life issues in dementia: Ambiguity among UK and Dutch physicians. Archives of Gerontology and Geriatrics, 65, 225-230. https://doi.org/10.1016/j.archger.2016.04.005, https://doi.org/10.1016/j.archger.2016.04.005

Published in:

Archives of Gerontology and Geriatrics

Document Version:

Peer reviewed version

Queen's University Belfast - Research Portal:

Link to publication record in Queen's University Belfast Research Portal

Publisher rights

(C) 2016 Elsevier Ireland Ltd.

This is an open access article published under a Creative Commons Attribution-NonCommercial-NoDerivs License

(https://creativecommons.org/licenses/by-nc-nd/4.0/), which permits distribution and reproduction for non-commercial purposes, provided the author and source are cited.

\section{General rights}

Copyright for the publications made accessible via the Queen's University Belfast Research Portal is retained by the author(s) and / or other copyright owners and it is a condition of accessing these publications that users recognise and abide by the legal requirements associated with these rights.

Take down policy

The Research Portal is Queen's institutional repository that provides access to Queen's research output. Every effort has been made to ensure that content in the Research Portal does not infringe any person's rights, or applicable UK laws. If you discover content in the Research Portal that you believe breaches copyright or violates any law, please contact openaccess@qub.ac.uk. 
Initiating advance care planning on end-of-life issues in dementia: ambiguity among UK and Dutch physicians

Jenny T. van der Steen, PhD, Karen Galway, BSc, MSc, PhD, Gillian Carter, BSc, BSc, PhD, and Prof. Kevin Brazil, PhD

Corresponding author: Jenny T. van der Steen

Leiden University Medical Center, Department of Public Health and Primary Care, Hippocratespad 21, Gebouw 3

P.O.Box 9600

2300 RC Leiden

Email: jtvandersteen@lumc.nl (email for submission and review procedures remains j.vandersteen@vumc.nl)

The Netherlands

and

Radboud university medical center

Department of Primary and Community Care

Nijmegen

The Netherlands

Affiliation KG (‥galway@qub.ac.uk), GC (g.carter@qub.ac.uk) and KB (k.brazil@qub.ac.uk): School of Nursing and Midwifery, Queen's University Belfast, 97 Lisburn Road, Belfast BT9 7BL, Ireland, United Kingdom

Word count text: 2821

Word count abstract: 250

2 Tables, 1 Figure

References: 24

Running head: advance care planning in dementia 


\section{ABSTRACT}

Background: In dementia, advance care planning (ACP) of end-of-life issues may start as early as possible in view of the patient's decreasing ability to participate in decision making. We aimed to assess whether practicing physicians in the Netherlands and the United Kingdom who provide most of the end-of-life care, differ in finding that ACP in dementia should start at diagnosis.

Methods: In a cross-sectional study, we surveyed 188 Dutch elderly care physicians who are on the staff of nursing homes and 133 general practitioners from Northern Ireland. We compared difference by country in the outcome (perception of ACP timing), rated on a 1-5 agreement scale. Regression analyses examined whether a country difference can be explained by contrasts in demographics, presence, exposure and role perceptions.

Results: There was wide variability in agreement with the initiation of ACP at dementia diagnosis, in particular in the UK but also in the Netherlands $(60.8 \%$ agreed, $25.3 \%$ disagreed and $14.0 \%$ neither agreed, nor disagreed). Large differences in physician characteristics (Dutch physicians being more present, exposed and adopting a stronger role perception) hardly explained the modest country difference. The perception that the physician should take the initiative was independently associated with agreeing with ACP at diagnosis.

Conclusions: There is considerable ambiguity about initiating ACP in dementia at diagnosis among physicians practicing in two different European health care systems and caring for different patient populations. ACP strategies should accommodate not only variations in readiness to engage in ACP early among patient and families, but also among physicians.

Keywords (MeSH terms): Advance care planning, dementia, end of life, palliative care 


\section{Introduction}

Advance care planning (ACP) can improve the quality of end-of-life care (1) and it fits well with the person-centred and anticipatory approach of palliative care $(2,3)$. Planning can start soon after diagnosis of an incurable or life-threatening progressive disease, or later. However, the optimal timing or how to assess the right moment in individual cases is unclear. In dementia, timing is crucial because the person may be involved in an early phase but not later through progressive cognitive decline. Research has shown that some people in the early stages are able, and may wish to talk about the future, but others resist looking ahead and rather live one day at a time $(4,5)$. Furthermore, some families even find ACP discussions soon after nursing home admission too early in view of the patient's health (6). There are many possible barriers to initiating ACP, including among professionals, such as not taking the initiative (7).

In a Delphi study by the European Association for Palliative Care (EAPC) however, most experts (most of whom were physicians) supported starting ACP early, if possible "as soon as the diagnosis is made" (8). Compared to expert views, practitioners' perceptions might vary more (9) and may also differ between countries because of greater influence of different health care systems and environments in which professionals operate locally. For example, in comparative studies, physicians' presence, certainty of family wishes and perceived responsibility for decision making (or paternalism) were greater in the Netherlands compared with the US and this may translate into different treatment approaches $(10,11)$.

In this paper, we address the question of whether practicing physicians in the Netherlands and the United Kingdom (UK) who provide most of the care at the end of life, differ in finding that ACP of end-of-life issues for people living with dementia should start at diagnosis. We examine a possible difference by country and whether this is explained by differences in demographics, presence, exposure and role perceptions between physicians in the two countries. 


\section{Methods}

We performed a cross-sectional survey among representative samples of physicians in the Netherlands and the UK. The UK survey has also been reported on elsewhere $(9,12)$; in this paper, we focus on cross-national differences in perceptions about advance care planning.

\subsection{Setting and sampling}

We selected the specialisms that assume primary responsibility for the care for persons with dementia often for years and including at the end of life. In the Netherlands, these are elderly care physicians who are certified after a 3-year specialty training (13). They are responsible for care for nursing home residents and part of the care for dementia patients in residential settings. In the Netherlands, $92 \%$ of patients with dementia die in nursing or residential homes (14). In different parts of the UK, this is half or slightly over half of the patients (50-61\% across Great Britain; 14), and the GP often remains responsible for the care. We hypothesized that the Dutch physicians would be much more in favour of early $\mathrm{ACP}$ because of their specialization, their training in $\mathrm{ACP}$, their greater exposure to patients with dementia, their different role perceptions and the fact that as ACP had not been previously commenced by the GP it is often only initiated by the Dutch physicians upon nursing home admission when the patient generally can no longer communicate effectively (15).

We aimed at about equal samples and a few hundred responses in total for regression analyses. In the Netherlands, we sampled one in four from an alphabetical list of surnames of the 1248 elderly care physicians who were member of the Dutch Association of Elderly Care Physicians and Social Geriatricians Verenso (almost all) and practicing autumn 2012. Of the 316 self-complete postal surveys we sent out in April 2013, 207 were returned and five were returned as undeliverable, resulting in a response rate of $66.6 \%(207 / 311)$. Nineteen of 207 were excluded from the analyses; 13 had no experience with patients dying with dementia and returned the survey not completed as instructed, and six were not providing any clinical care currently due to illness or for other reasons.

In the UK, the self-complete postal survey was sent to 340 GPs located across Northern Ireland in 2013, the region that has identified the highest dementia diagnoses rates in the UK, (16), and represented 174 practices (49\% of all practices in Northern 
Ireland). The response rate was $40.6 \%$ (138/340) representing $60.9 \%$ of the surveyed practices (106/174) and 133 surveys were complete and available for analyses.

\subsection{Procedures}

To maximize responses, an incentivizing prize draw was held in each jurisdiction, to win an iPad mini in the UK and 100 euro gift cards in Netherlands. In the Netherlands, we sent another copy of the survey to non-responders in May and in June 2013. In the UK, a system of up to four mail contacts was implemented (17). We assured confidential processing of the answers. Survey data was inputted and managed using Blaise which features e.g., range checks (version 4.7.1, 2008, Statistics Netherlands, The Hague) and IBM SPSS Statistics 21, 2012 (UK).

In the Netherlands, the procedure was approved by the Medical Ethics Review Committee of the VU University Medical Center as part of a series of studies on end-of-life care. In the UK, ethical approval was obtained through the Research Ethics Committee, School of Nursing and Midwifery, Queen's University Belfast.

\subsection{Items}

We assessed physician and practice characteristics in some detail using the same items preparing for the cross-national comparison. The form was translated into Dutch and we discussed and resolved any discrepancies with a back translation by a professional translator.

The outcome was the level of agreement with the statement "Advance care planning on end of life care should be initiated at the time of diagnosis of dementia" (EAPC recommendation 3.2 which is also a statement, but shortened). We developed additional statements for the purpose of the survey. All used the response options: strongly disagree, moderately disagree, neither agree nor disagree, moderately agree, strongly agree, and don't know. The physicians were shown the scale with numbers running from 1-5 (and 0 for don't know).

We measured exposure through asking for experience as a physician and the estimated number of dying dementia patients cared for in the past year by the respondent. Presence was measured with a $0-12$ scale that added up practice time involving clinical care in the nursing home and frequency of visiting a typical nursing home patient (11). Role 
perception regarding ACP was measured with two agreement items: "The physician should take the initiative to introduce and encourage advance care planning," and "The advance care planning process requires making family members agree with the physician on goals of care."

\subsection{Analyses}

We compared differences between countries on the outcome of whether ACP should start at diagnosis, and three key variables expected to differ cross-nationally while potentially related to the outcome: exposure, presence and role perception. We used chisquare tests to compare dichotomous variables, and t-tests for normally distributed age and experience, and the non-parametric Mann-Whitney $U$ test or hierarchical gamma test if distributions deviated from the normal distribution. Next, we used univariable and multivariable linear regression analyses to examine if the outcome was associated with country, demographics, exposure, presence or role perception, and in particular, if any country difference in agreement was affected by differences in the other variables. We examined possible co-linearity of age and experience with Pearson's correlation. The level of significance was 0.05 .

The analyses were performed with SPSS 20.0.0.2 (IBM, 2011). Missing data were at most 3\% (in the presence scale). With missing values, for multiple regression only, we imputed with mean or mode stratified by country. 


\section{Results}

Table 1 shows that the Dutch physicians differed from their UK colleagues on all characteristics except for age. The Dutch physicians were more frequently female, less experienced, and more frequently provided part time clinical care. Nevertheless, they had cared for more dying dementia patients (e.g., 20 or more in the previous year: $29.9 \%$ versus $5.4 \%$, respectively), and they were more present in the nursing home (e.g., most physicians seeing the patient daily).

While most physicians agreed that the physician should take the initiative to introduce and encourage ACP, more Dutch physicians agreed compared to their Northern Irish counterparts (92.5\%, 173/187 agreed moderately or strongly, versus $82.7 \%, 110 / 133$ ). Role perception varied more regarding whether the physician should make families agree with care goals. The Dutch physicians typically agreed (median: moderately agree; $87.6 \%$ agreed moderately or strongly, 163/186) whereas physicians from Northern Ireland typically disagreed (median: moderately disagree) but with wide variability (27.8\% agreed, 37/133; interquartile range: 2 ).

In both countries, there was wide variability in agreement with ACP on end-of-life care initiated at diagnosis (Figure 1), in particular in the UK; almost as many physicians agreed (moderately or strongly, 39.8\%) as disagreed (moderately or strongly, 45.9\%). Most Dutch physicians (60.8\%) agreed, but a sizeable minority (25.3\%) disagreed. The difference in means was only modest with 3.4 (SD 1.2) for the Dutch physicians, and 2.9 (SD 1.3) for the physicians from the UK $(P<0.001)$.

A significant difference of about half a point on the agreement scale (unadjusted, 0.52; Table 2) was retained with adjustment with demographics only $(-0.49, \mathrm{Cl}-0.78 ;-0.20)$. When examining whether the differences in demographics, as well as presence, exposure and role perceptions between physicians in the two countries influenced the physicians' perceptions on timing of introducing ACP, we found that the differences between physicians did not affect the difference in perception of ACP; the difference was the same (although no longer significant; $-0.49, \mathrm{Cl}-1.05 ; 0.06 ; P=0.08)$. The single independent predictor was a stronger role perception regarding that the physician should take the initiative to introduce and encourage $\operatorname{ACP}(0.24, \mathrm{Cl} 0.06 ; 0.43)$. In addition to country, it was also the only significant association in univariable analyses $(0.14, \mathrm{Cl} 0.03 ; 0.26)$. The results were the same with adjustment for experience which correlated strongly with age (Pearson $r=0.93$; 
$P<0.001)$. Neither the model with country only $(4 \%)$ nor the adjusted model $(7 \%)$ explained much of the variance in the outcome agreement with ACP should start at diagnosis. 


\section{Discussion}

\subsection{Main findings}

There is considerable ambiguity about initiating ACP about end-of-life issues in dementia at diagnosis among primary care physicians with different specialties in two European countries. The diversity of perceptions in both the Netherlands and in the United Kingdom (Northern Ireland) was not clearly explained by country. More specifically, differences in demographics and contextual factors related to the health care system such as the Dutch elderly care physicians being more present and exposed to patients dying with dementia than the GPs from the UK did not matter. The only independent predictor was a stronger role perception; physicians who felt they should take the initiative were more likely to agree that ACP should start at diagnosis. Therefore, even in these very different physician populations and health care systems, there were similarly (wide) distributions of perceptions about initiating ACP.

\subsection{Strengths and limitations}

The response of GPs based in the UK was low. However, a $40.6 \%$ response rate is common for physician surveys and $60.9 \%$ of practices were represented. The Dutch rate of $66.6 \%$ was high also compared to the $47.4 \%$ response to a previous survey in Dutch elderly care physicians, about advance directives and euthanasia, with one reminder (18). We did not define style or type of initiation of ACP in terms of goals or treatments, but referred to any first action the physicians regarded as ACP. The statistical power was reduced in adjusted analyses and therefore half a point difference on the 1-5 agreement scale was significant only in unadjusted analyses. Nevertheless, the results point to diversity in opinions of individual physicians as a major source of variance which may be explained better by, e.g., their beliefs about treatment futility, life view, personality, or other psychological factors rather than factors related to different health-care systems, settings and patient populations. If we had found clearly different distributions between the two countries, we may not have been able to link this to the source because of other differences in health care services which we did not measure, or differences in patient populations, and perhaps personal and cultural beliefs.

\subsection{Comparison with literature}


Swiss GPs have shown remarkable diversity regarding the right moment of ACP more generally (19). The diversity among physicians might represent the same variability in readiness to plan ahead as found with families and patients with dementia $(4,5,7)$. In contrast, $90 \%$ of the EAPC expert panel agreed with the recommendation "Anticipating progression of the disease, ACP is proactive. This implies it should start as soon as the diagnosis is made, when the patient can still be actively involved and patient preferences, values, needs and beliefs can be elicited (8)." It is possible that this longer statement about ACP at diagnosis that also emphasized its urgency resulted in higher agreement. (The EAPC white paper explanatory text calls for "respect for patient's choice if they should not wish to engage in ACP" but few experts read this.) Perhaps our samples of practicing physicians more strongly considered issues such as time constraints or patient (un)readiness. This might also explain slightly less enthusiasm (referring to unadjusted analyses only) on part of GPs from the UK who may diagnose dementia relatively often in a community setting. The context is widely different with Dutch elderly care physicians diagnosing dementia in nursing home residents admitted because of physical problems, who reside on "somatic units" rather than "psychogeriatric units" or also specialised units for people with young-onset dementia for individuals with a dementia diagnosis upon nursing home admission. This is after a transition to the nursing home setting where ACP is common, and ACP at diagnosis might be a less sensitive issue once people are in the nursing home and perhaps perceived as closer to the end of life than in the community setting.

Physicians who felt they should take the initiative may have been more in favour of ACP overall, being convinced of its benefits. Possibly, physicians hold strong beliefs about benefits of ACP, as with some other end-of-life decision making. Qualitative research among Dutch and German physicians found that they generally adhere to either a proactive strategy presenting hypothetical future scenarios regarding health problems and treatment, or a responsive strategy, waiting for the patient to decline $(15,20)$. Perceived self-efficacy may be important as physicians in favour of early ACP may be more confident of their skills or capability to overcome barriers such as lack of time.

\subsection{Implications for research and practice}

Our study therefore raises a number of hypotheses. Societal developments such as a wish for more shared decision making and person-centred care underpin the need to 
promote ACP for those willing to engage in it, and physicians are in a key position to initiate it. Dementia-specific formats are being developed to facilitate dialogue by adopting a structured approach, whether stand-alone or ACP integrated in the care e.g., in the UK (21), and the US (22). An important question, with fundamentally different stances about the value of planning, is should we also respect the views of physicians unwilling to engage in it? Perhaps professional norms can require them to probe patient's and family's readiness for ACP gently to not overwhelm people, and if needed, refer to other professionals. Regardless, we encourage awareness of physician's own stance and of differences that evidently exist between all - whether professionals or patient/family and perhaps general public - and we train them to employ different strategies for optimal patient- and family-centred caregiving. Training that considers personal views with an eye on reluctance, openness to discuss barriers and possible perceived undesirable side effects, may be needed in addition to guidelines, even if they do refer to variable readiness, e.g. those from EAPC or national UK guidelines that state that ACP preferably occurs before admission to a nursing home (23). A lack of confidence in discussing end-of-life care and lack of understanding of the options at the end of life among health care professionals have been called easier to tackle than the challenges in advance care planning in dementia that are related to service configuration, patient, illness, and general public (24).

Future research may study what other timing is being preferred and the influence of developing longstanding physician-patient/family relationships and personality. Also, perceptions of neurologists and geriatricians may be examined. More in-depth study is needed on barriers and facilitators of ACP in early stages, preferably with longitudinal, intervention or mixed-methods studies that record readiness of patients, families and professionals. Promoting public awareness may help develop a shared understanding of ACP in dementia.

\subsection{Conclusion}

Physicians responsible for care at the end of life of patients with dementia in two different European health care systems varied in similar ways in their perceptions about initiating ACP in dementia at diagnosis. European-level guidance for practice and training should consider physicians' variable readiness to engage in ACP. 


\section{Funding}

Funding was provided by the Care to Know Centre, Ontario, Canada, and by the Aspasia supplement to a career award for JTS provided by the Netherlands Organisation for Scientific Research (NWO; Innovational Research Incentives Scheme) Vidi grant number 91711339.

\section{Acknowledgements}

We thank Giselka Gutschow, MA for help in formatting the survey, administration, and data entry, and Rommy de Jong, MD for her helpful comments to an earlier version of the manuscript.

\section{Declaration of interest}

We declare we have no competing interests. The authors alone are responsible for the content and writing of the paper. 


\section{References}

1. Brinkman-Stoppelenburg A, Rietjens JA, van der Heide A. The effects of advance care planning on end-of-life care: a systematic review. Palliat Med 2014;28:1000-25.

2. World Health Organization (WHO). Definition of palliative care, 2002. http://www.who.int/cancer/palliative/definition/en/ (accessed at 3 December 2015)

3. European Association for Palliative Care (EAPC). White paper on standards and norms for hospice and palliative care in Europe: part 1. European Journal of Palliative Care 2009;16:278-89.

4. Hirschman KB, Kapo JM and Karlawish JH. Identifying the factors that facilitate or hinder advance planning by persons with dementia. Alzheimer Dis Assoc Disord 2008;22:293-8.

5. de Boer ME, Droes RM, Jonker C, Eefsting JA, Hertogh CMPM. Thoughts on the future: The perspectives of elderly people with early-stage Alzheimer's disease and the implications for advance care planning. AJOB Primary Research 2012;3:14-22.

6. van Soest-Poortvliet MC, van der Steen JT, de Vet HCW, Hertogh CMPM, Onwuteaka-Philipsen BD, Deliens LH. Factors related to establishing a comfort care goal in nursing home patients with dementia: a cohort study among family and professional caregivers. J Palliat Med 2014;17:131727.

7. van der Steen JT, van Soest-Poortvliet MC, Hallie-Heierman M, Onwuteaka-Philipsen BD, Deliens L, de Boer ME, et al. Factors associated with initiation of advance care planning in dementia: a systematic review. J Alzheimers Dis 2014;40:743-57.

8. van der Steen JT, Radbruch L, Hertogh CMPM, de Boer ME, Hughes JC, Larkin P, et al.; European Association for Palliative Care (EAPC). White paper defining optimal palliative care in older people with dementia: a Delphi study and recommendations from the European Association for Palliative Care. Palliat Med 2014;28:197-209.

9. Brazil K, Carter G, Galway K, Watson M, van der Steen JT. General practitioners perceptions on advance care planning for patients living with dementia. BMC Palliat Care 2015;14(1):14.

10. Helton MR, van der Steen JT, Daaleman TP, Gamble GR, Ribbe MW. A cross-cultural study of physician treatment decisions for demented nursing home patients who develop pneumonia. Ann Fam Med 2006;4:221-7.

11. Helton MR, Cohen LW, Zimmerman S, van der Steen JT. The importance of physician presence in nursing homes for residents with dementia and pneumonia. J Am Med Dir Assoc 2011;12:68-73.

12. Carter G, van der Steen JT, Galway K, Brazil K. General practitioners' perceptions of the barriers and solutions to good quality palliative care in dementia. Dementia 2015;April 16, epublished ahead of print.

13. Koopmans RTCM, Lavrijsen JC, Hoek JF, Went PB, Schols JM. Dutch elderly care physician: a new generation of nursing home physician specialists. J Am Geriatr Soc 2010;58:1807-9.

14. Houttekier D, Cohen J, Bilsen J, Addington-Hall J, Onwuteaka-Philipsen BD, Deliens L. Place of death of older persons with dementia. A study in five European countries. J Am Geriatr Soc 2010;58:751-6. 
15. van Soest-Poortvliet MC, van der Steen JT, Gutschow G, Deliens L, Onwuteaka-Philipsen BD, de Vet $\mathrm{HCW}$, et al. Advance care planning in nursing home patients with dementia: a qualitative interview study among family and professional caregivers. J Am Med Dir Assoc 2015;16:979-89.

16. UK Alzheimer's Society. Dementia diagnosis rates 2014.

http://www.alzheimers.org.uk/site/scripts/documents info.php?documentID=2165 (accessed at 3 December 2015)

17. Dillman D, Smyth J, Christian LH. Internet, Mail and Mixed-Mode Surveys: The Tailored Design Method.3rd ed. Hoboken, New Jersey: John Wiley \& Sons, 2009.

18. de Boer ME, Dröes RM, Jonker C, Eefsting JA, Hertogh CM. Advance directives for euthanasia in dementia: how do they affect resident care in Dutch nursing homes? Experiences of physicians and relatives. J Am Geriatr Soc 2011;59:989-96.

19. Otte IC, Jung C, Elgera BS, Bally K. Advance directives and the impact of timing: A qualitative study with Swiss general practitioners. Swiss Med Wkly 2014;144:w14035.

20. Pfeil TA, Laryionava K, Reiter-Theil S, Hiddemann W, Winkler EC. What keeps oncologists from addressing palliative care early on with incurable cancer patients? An active stance seems key. Oncologist 2015;20:56-61.

21. Elliott M, Harrington J, Moore K, Davis S, Kupeli N, Vickerstaff V, et al. A protocol for an exploratory phase I mixed-methods study of enhanced integrated care for care home residents with advanced dementia: the Compassion Intervention. BMJ Open 2014;4(6):e005661.

22. Einterz SF, Gilliam R, Lin FC, McBride JM, Hanson LC. Development and testing of a decision aid on goals of care for advanced dementia. J Am Med Dir Assoc 2014;15:251-5.

23. Royal College of Physicians, National Council for Palliative Care, British Society of Rehabilitation Medicine, British Geriatrics Society, Alzheimer's Society, Royal College of Nursing, Royal College of Psychiatrists, Help the Aged, Royal College of General Practitioners. Advance care planning. Concise Guidance to Good Practice series, No 12. London: RCP, 2009. www.rcplondon.ac.uk/guidelines-policy/advance-care-planning (accessed at 3 December 2015) 24. Brown J. Advance care planning in dementia. Lancet Psychiatry 2015;2:774-5. 
Table 1. Characteristics of the physicians in the Netherlands and the UK.

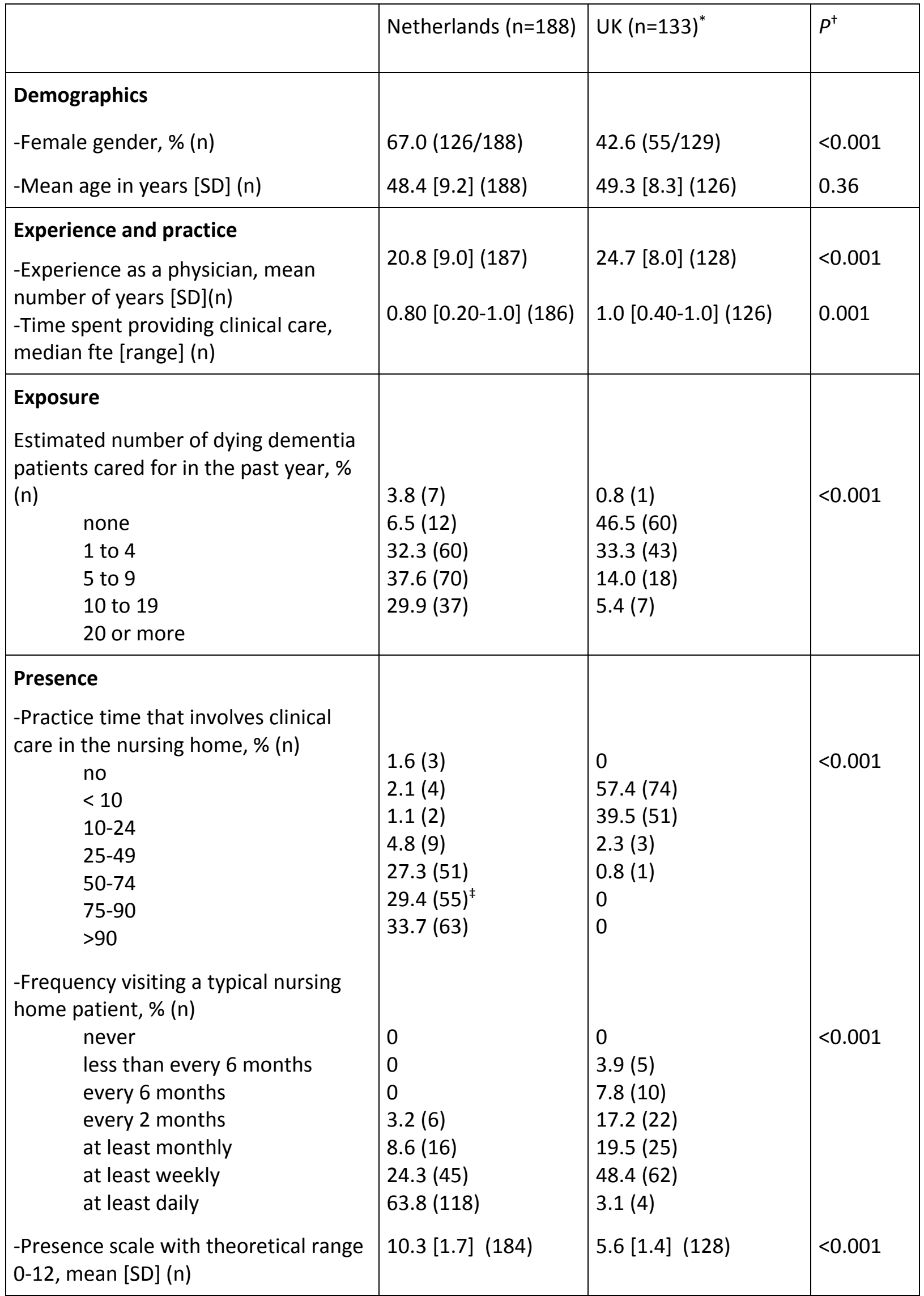




\begin{tabular}{|l|l|l|l|}
\hline $\begin{array}{l}\text { Role perception, } 1-5 \text { agreement } \\
\text { scales, median [range; interquartile } \\
\text { range] }(n)\end{array}$ & . & & \\
$\begin{array}{l}\text {-The physician should take the } \\
\text { initiative to introduce and encourage } \\
\text { advance care planning }\end{array}$ & $\begin{array}{l}5, \text { strongly agree } \\
{[2-5 ; 1](187)}\end{array}$ & $\begin{array}{l}4, \text { moderately agree } \\
{[1-5 ; 1](133)}\end{array}$ & $<0.001$ \\
$\begin{array}{l}\text {-The advance care planning process } \\
\text { requires making family members } \\
\text { agree with the physician on goals of } \\
\text { care }\end{array}$ & $\begin{array}{l}4, \text { moderately agree } \\
{[1-5 ; 1](186)}\end{array}$ & $\begin{array}{l}2, \text { moderately } \\
\text { disagree }[1-5 ; 2](133)\end{array}$ & $<0.001$ \\
\hline
\end{tabular}

*Four physicians did not complete the section with physician characteristics. Also note that most of the characteristics of the UK physicians have been published as well in Brazil et al. (9)

${ }^{+}$t-test or Chi square test unless indicated otherwise; for skewed distributions, we used a Mann Whitney $\mathrm{U}$ test (Time spent providing clinical care) and gamma tests (Exposure, Presence, Role perception).

${ }^{\ddagger}$ One physician circled both $50-74 \%$ and $75-90 \%$; we analysed as in-between but present it combined with the larger $75-90 \%$ proportion. 
Table 2. Associations of country and other variables with physicians' agreement with advance care planning $(A C P)$ at diagnosis $(n=321)$.

\begin{tabular}{|c|c|}
\hline Model & $\begin{array}{l}\text { Beta for level of } \\
\text { agreement with ACP at } \\
\text { diagnosis }(95 \% \mathrm{Cl})\end{array}$ \\
\hline $\begin{array}{l}\text { Univariable } \\
\text {-Country (UK versus Netherlands) unadjusted }\end{array}$ & $-0.52(-0.80 ;-0.24)^{*}$ \\
\hline \multicolumn{2}{|l|}{ Multivariable } \\
\hline -Country (UK versus Netherlands) adjusted & $-0.49(-1.05 ; 0.06)$ \\
\hline Female gender & $0.02(-0.28 ; 0.32)$ \\
\hline Age, per year increment & $0.005(-0.011 ; 0.021)$ \\
\hline Greater exposure (to dying patients, per category) & $0.007(-0.14 ; 0.16)$ \\
\hline Greater presence (per point increment on presence scale) & $0.01(-0.08 ; 0.11)$ \\
\hline $\begin{array}{l}\text { Stronger role perception: agreed physician initiative (per point } \\
\text { increment) }\end{array}$ & $0.24(0.06 ; 0.43)^{*}$ \\
\hline $\begin{array}{l}\text { Stronger role perception: agreed make family agree (per point } \\
\text { increment) }\end{array}$ & $-0.09(-0.23 ; 0.06)$ \\
\hline
\end{tabular}

* Significant differences in italics 


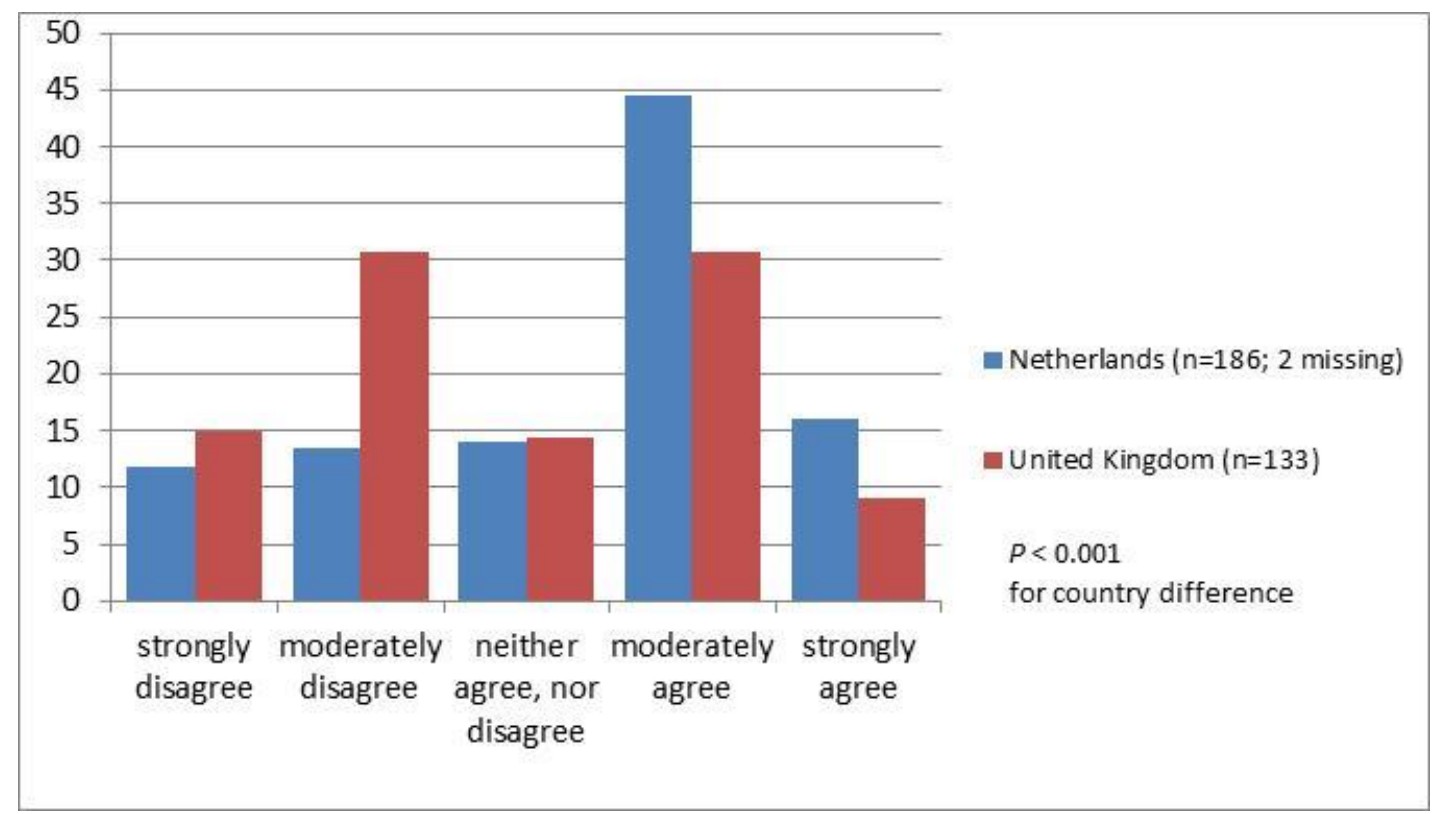

Figure 1. Physicians' agreement with advance care planning (ACP) at diagnosis by country (percentages) 